\title{
Direct observation of voids in the vacancy excess region of ion bombarded silicon
}

\author{
J. S. Williams, ${ }^{\text {a) }}$ M. J. Conway, B. C. Williams, and J. Wong-Leung \\ Department of Electronic Materials Engineering, Research School of Physical Sciences and Engineering, \\ The Australian National University, Canberra ACT 0200, Australia
}

(Received 18 September 2000; accepted for publication 3 January 2001)

\begin{abstract}
The results reported in this letter indicate that the spatial separation of the vacancy and interstitial excesses which result from ion bombardment gives rise to stable voids upon annealing at $850{ }^{\circ} \mathrm{C}$ even for implants where the projected ion range is only of the order of a few thousand Angstrom. Such voids have been observed directly by transmission electron microscopy. Furthermore, in cases where both voids and interstitial-based defects are present at different depths, it is found that Au has a strong preference for decorating void surfaces and hence Au can, indeed, be used as a selective detector of open volume defects in Si. (C) 2001 American Institute of Physics.
\end{abstract}

[DOI: $10.1063 / 1.1352662$ ]

Ballistic processes which occur during implantation into Si lead directly to a local vacancy excess at depths up to about half the projected ion range and an interstitial excess at deeper depths close to the ion range. ${ }^{1}$ However, there is considerable interest as to the stability of such defects and their evolution during annealing. ${ }^{2-5}$ Whereas interstitial-based $\{311\}$ defects and loops ${ }^{2-4}$ are easily observed by transmission electron microscopy (TEM), vacancy clusters and voids have been extremely difficult to observe directly. ${ }^{5}$ Nevertheless, voids have been observed by TEM after annealing of $\mathrm{MeV}$ implants to high doses, ${ }^{6,7}$ where the separation of the vacancy and interstitial excesses is large, and also inferred ${ }^{8}$ from contrast in TEM images following high dose $\mathrm{keV}$ implants. However, as a result of this difficulty of observing voids, indirect methods have been used to determine vacancy excesses such as positron annihilation ${ }^{9}$ and also labelling of vacancy clusters by fast diffusing metals, ${ }^{5,10,11}$ such as $\mathrm{Au}$. Positron annihilation is sensitive to open volume defects but the vacancy concentration needs to be high $\left(\sim 4 \times 10^{16} \mathrm{~cm}^{-2}\right) .{ }^{12}$

It is well known that fast diffusing metals are efficiently trapped at nanocavities in silicon ${ }^{13,14}$ and these larger open volume defects are easily observable by TEM. However, there is some debate as to whether metals are selectively gettered to vacancy clusters in the presence of interstitialbased defects. Some authors ${ }^{15}$ suggest, for example, that metal decoration at defects which are not observable by TEM at around half the projected range $\left(R_{p} / 2\right)$ may not be proof that stable vacancy clusters exist in this region. However, the recent $\mathrm{Au}$ decoration studies of so called $R_{p} / 2$ defects for $\mathrm{MeV}$ implants ${ }^{10,11}$ is quite convincing in arguing for the presence of vacancy clusters.

In this study we set out to directly observe vacancyrelated defects in TEM for $\mathrm{keV}$ implantations and to attempt to resolve the issue of open volume defects being preferential trapping sites for fast diffusing $\mathrm{Au}$.

Czochralski $(\mathrm{Cz}) \mathrm{Si}(100)$ wafers (n-type 5-10 $\Omega \mathrm{cm}$ ) were implanted with $245 \mathrm{keV} \mathrm{Si}^{+}$ions at $100^{\circ} \mathrm{C}$ to doses in

${ }^{a)}$ Electronic mail: jsw109@rsphysse.anu.edu.au the range $8 \times 10^{14}-6 \times 10^{16} \mathrm{~cm}^{-2}$. The base pressure during implantation was better than $10^{-7}$ Torr. The projected ion range $R_{p}$ for $245 \mathrm{keV} \mathrm{Si}^{+}$ions in $\mathrm{Si}$ is $3800 \AA$, as obtained from TRIM95 simulations. ${ }^{16}$ Such simulations were also used to provide the excess vacancy and interstitial distributions, as shown in Fig. 1. It is clear that collisional processes lead to an excess of vacancies from the surface up to a depth of about $R_{p} / 2$, whereas the interstitial excess (which includes the implanted ions themselves) is located at depths close to $R_{p}$. Following implantation, samples were annealed at $850^{\circ} \mathrm{C}$ for $1 \mathrm{~h}$ to allow defect annihilation and/or clustering into defects visible by TEM. Selected samples had a 5 $\times 10^{13} \mathrm{~cm}^{-2} \mathrm{Au}$ implant at $30 \mathrm{keV}$ prior to annealing $\left(R_{p}<200 \AA\right)$ to allow Au decoration of defects during subsequent annealing at $8500^{\circ} \mathrm{C}$. Samples were analyzed before and after annealing by Rutherford backscattering and channeling (RBSC) using $1.8 \mathrm{MeV} \mathrm{He}{ }^{+}$ions to monitor implantation damage and Au distributions. Selected samples were analyzed by cross-sectional TEM (XTEM) using a CM 300 instrument operated at $200 \mathrm{keV}$ in order to study the nature of residual defects.

Figure 2 shows RBS profiles of $\mathrm{Au}$ for two $\mathrm{Si}^{+}$doses, $3 \times 10^{15} \mathrm{~cm}^{-2}$ and $1.4 \times 10^{16} \mathrm{~cm}^{-2}$, after annealing at $850{ }^{\circ} \mathrm{C}$. For the lower $\mathrm{Si}^{+}$dose case, about $35 \%$ of the $\mathrm{Au}$ is located in a broad peak centred at about $900 \AA$. The remainder of the Au remains at the surface, presumably where it has precipitated. Based on the recent report of Kalyanaraman et al. ${ }^{11}$ this result would suggest that Au has completely filled the residual open volume defects in the sample. Using their calculated value of 1.2 vacancies per $\mathrm{Au}$ atom, this would give the number of vacancies bound up in such clusters as $3 \times 10^{13} \mathrm{~cm}^{-2}$ for a dose of $3 \times 10^{15} \mathrm{Si} \mathrm{cm}^{-2}$ at $100{ }^{\circ} \mathrm{C}$. The higher $\mathrm{Si}^{+}$dose case in Fig. 2 shows that almost all the Au has distributed to depths between the surface and $R_{p} / 2$. This result would suggest that there is insufficient $\mathrm{Au}$ to saturate the open volume defects. It is interesting that there is a double peak in the Au profile in this case (see second peak at $2400 \AA$ ), a feature we will return to later. In addition, there is a zone near the surface $(<200 \AA)$ which is denuded of any Au. This region corresponds to a surface 


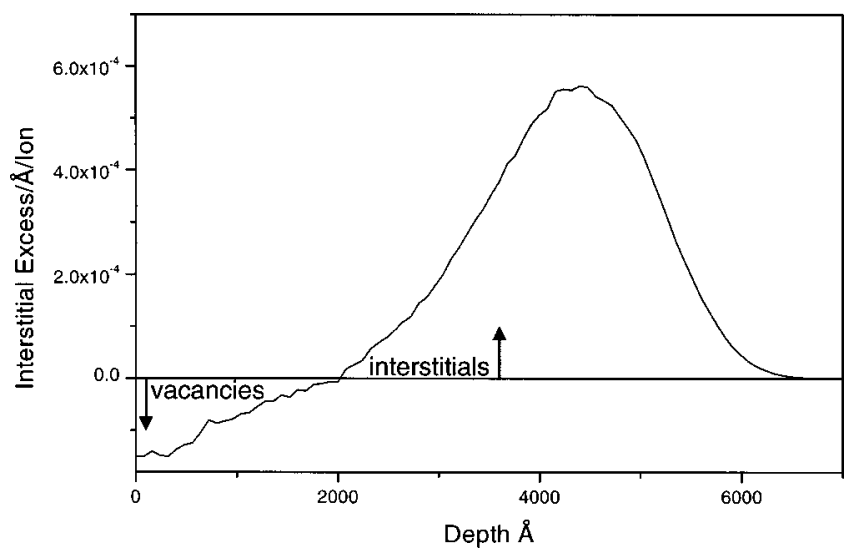

FIG. 1. TRIM simulations using full cascades, illustrating the vacancy and interstitial excesses as a function of depth for $245 \mathrm{keV} \mathrm{Si}$ ions incident on a Si sample. The incident ions are included in the interstitial excess.

layer which has been amorphized by the Au implant. Amorphization would be expected to destroy any residual defects emanating from the prior $245 \mathrm{keV} \mathrm{Si}{ }^{+}$implant.

In Fig. 3(a), we show a cross-sectional TEM micrograph corresponding to the higher dose case in Fig. 2. Considerable residual disorder follows the $850{ }^{\circ} \mathrm{C}$ annealing in this case. However, the visible defects are essentially all interstitialbased dislocation loops and tangles. Comparing the depth distribution of this visible damage with the corresponding $\mathrm{Au}$ distribution from Fig. 2, it is clear that most of the Au lies at depths where no visible dislocations are present. In Fig. 3(b) we show RBSC spectra illustrating the residual disorder before and after annealing. Before annealing, the disorder peak in RBSC just reaches the random level but is not completely amorphous at this dose, suggested by the nature of the residual defects observed in the XTEM after annealing [Fig. 3(a)]. The RBSC spectrum after annealing shows a little residual disorder beginning at about $3500 \AA$, illustrating the low sensitivity of RBSC to moderate concentrations of extended defects.

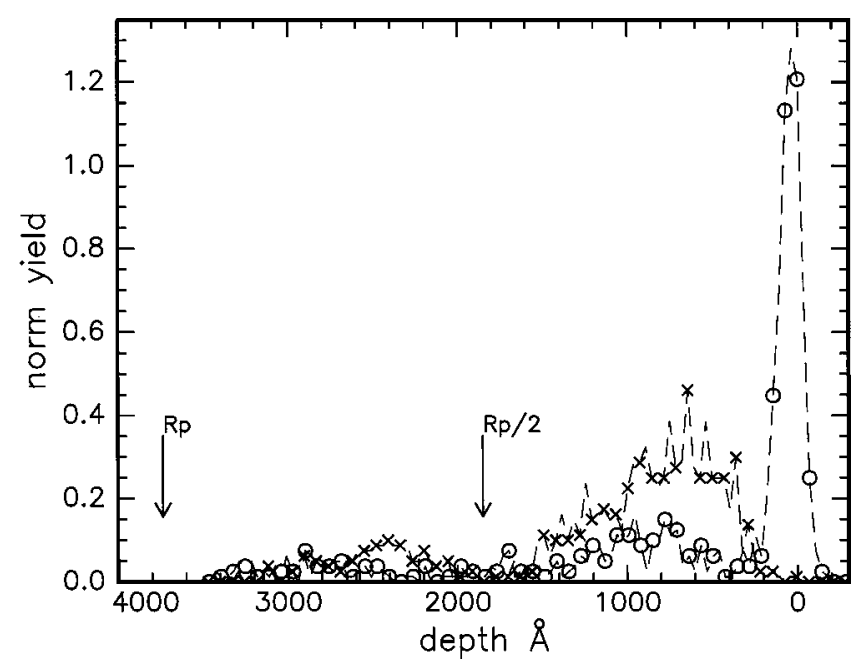

FIG. 2. RBS spectra of Au profiles after annealing at $850^{\circ} \mathrm{C}$ for $1 \mathrm{hr}$ of $\mathrm{Si}$ samples previously implanted with $245 \mathrm{keV} \mathrm{Si}^{+}$ions at $100{ }^{\circ} \mathrm{C}$ to doses of $3 \times 10^{15} \mathrm{~cm}^{-2}$ (open circles) and $1.4 \times 10^{16} \mathrm{~cm}^{-2}(\times)$. After Si implantation a $30 \mathrm{keV} \mathrm{Au}$ implant to a dose of $5 \times 10^{13} \mathrm{~cm}^{-2}$ was carried out at

room temperature.
Downloaded 10 Oct 2007 to 150.203 .178 .60 . Redistribution subject to AIP license or copyright, see http://apl.aip.org/apl/copyright.jsp

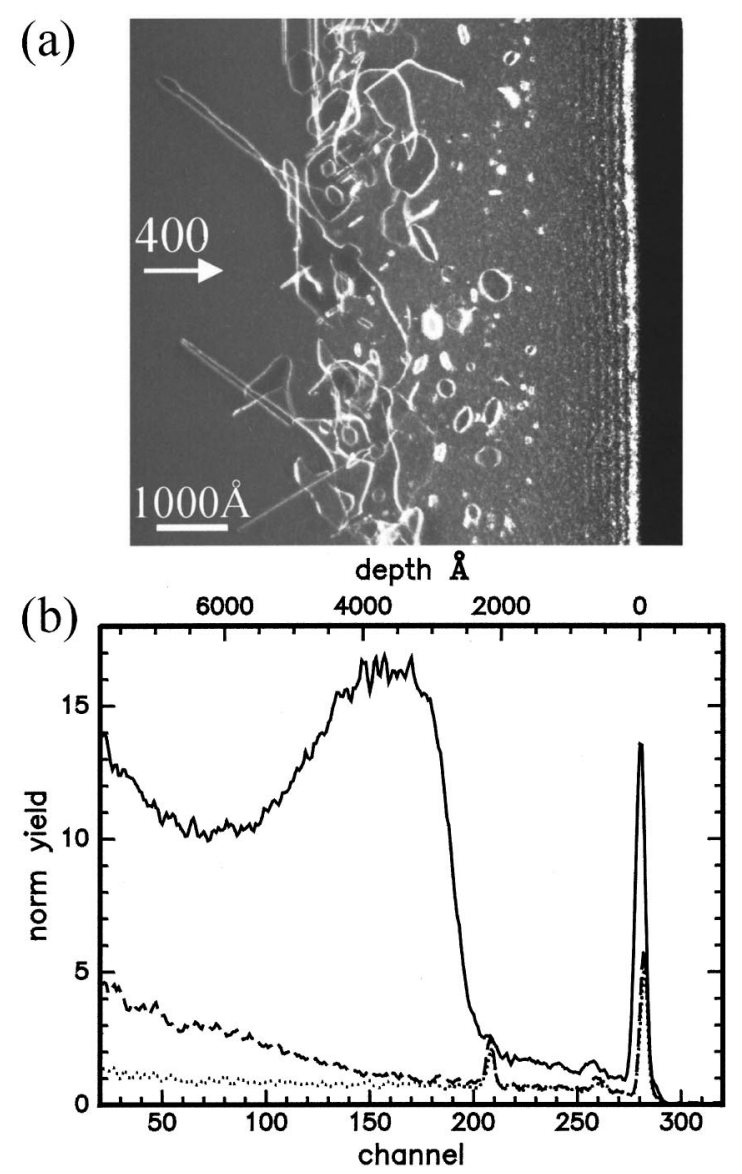

FIG. 3. (a) XTEM micrograph of the $1.4 \times 10^{16} \mathrm{~cm}^{-2}$ sample from Fig. 2. (b) RBSC spectra of this same sample before (solid curve) and after (dashed curve) annealing at $850{ }^{\circ} \mathrm{C}$. The dotted curve depicts a spectrum from an unimplanted sample.

In order to determine what defects are decorated by the $\mathrm{Au}$, higher magnification XTEM was examined. Figure 4 shows such a TEM micrograph for the $1.4 \times 10^{16} \mathrm{Si} \mathrm{cm}^{-2}$ dose after annealing, clearly showing the presence of voids. The top of the micrograph is about $460 \AA$ from the surface of

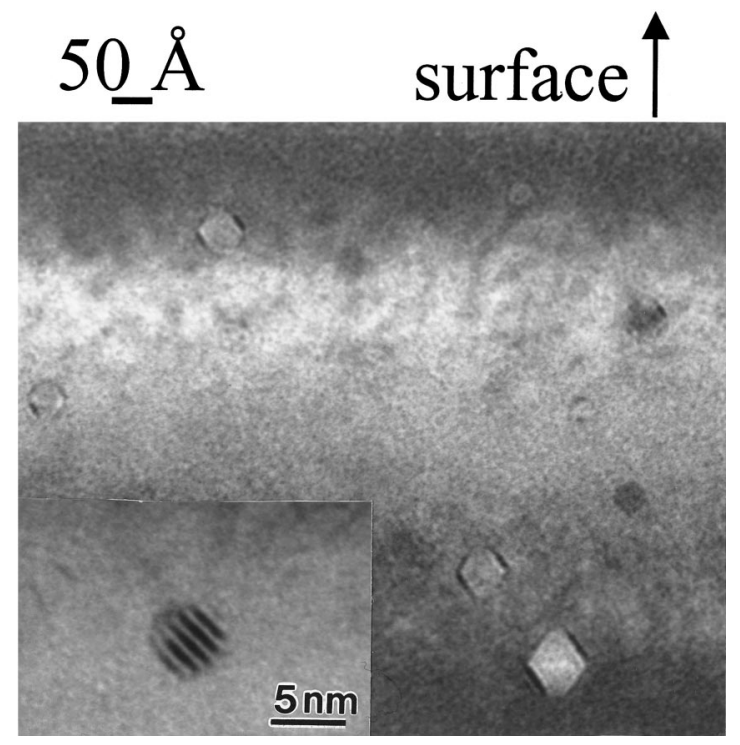

FIG. 4. XTEM micrograph from a depth (460-1100 $\AA$ from the surface) corresponding to the region denuded of interstitial-based defects but containing $\mathrm{Au}$ for the $1.4 \times 10^{16} \mathrm{~cm}^{-2}$ sample from Fig. 2. The inset shows a precipitate which is presumably Au rich 
the sample, whereas the bottom of the micrograph corresponds to a depth of about $1100 \AA$ from the surface. This region has been shown to be devoid of visible defects in the lower magnification micrograph in Fig. 3(a). Figure 4 is taken slightly out of focus to improve imaging of voids. The voids are well faceted and about $50 \AA$ in size. Through-focal imaging of the voids showed $Z$-contrast arising from the $\mathrm{Au}$ decoration of the walls of the voids as has been previously observed for the case of $\mathrm{Au}$ gettering to much larger nanocavities. ${ }^{13}$

XTEM analysis of the sample also revealed the presence of occasional precipitates which have a similar size to the voids. These precipitates sometimes exhibit well defined Moiré fringes (see inset), which are indicative of a crystalline phase with a different lattice spacing to that of the Si matrix, presumably an Au rich phase. We propose that, as has been well established for nanocavities in $\mathrm{Si}_{1}{ }^{17}$ when the Au concentration exceeds that required to saturate the void walls at around a monolayer of coverage, it then begins to fill the open volume of the voids. It would appear that when all the open volume is filled by $\mathrm{Au}$, the excess Au prefers to precipitate at the surface rather than decorate interstitial-based defects. Our observations for lower and higher $\mathrm{Si}^{+}$doses than the $1.4 \times 10^{16} \mathrm{~cm}^{-2}$ case, illustrated in Figs. 2, 3, and 4, are consistent with this behavior.

Voids have only previously been observed at depths less than the projected range for oxygen ${ }^{6,7}$ and phosphorous ${ }^{8}$ implanted Si. This raises the question as to whether impurities or a chemical effect might be responsible for stabilizing voids during annealing. In our case of $\mathrm{Si}^{+}$implantation, such an impurity or chemical effect could only arise from background impurities in the $\mathrm{Si}$ itself (such as oxygen in $\mathrm{Cz} \mathrm{Si}$ ) or from recoil implanted oxygen. ${ }^{18}$ Based on the low partial pressure of oxygen under our implantation conditions, we believe we can rule out any role of recoiled oxygen. In the case of background oxygen (or carbon) in the Si itself, there may be some role in the initial trapping of vacancies but it is unlikely that such impurities play a major role in their subsequent coalescence into voids. For example, annealing temperatures of $950{ }^{\circ} \mathrm{C}$ for several hours are required to redistribute oxygen to nanocavities in $\mathrm{Si},{ }^{19}$ whereby oxygen ejects Au from cavity walls.

The deeper Au peak in Fig. 2, at about $2400 \AA$ for the $1.4 \times 10^{16} \mathrm{Si} \mathrm{cm}^{-2}$ case, deserves some discussion. From Fig. 3(a), this Au resides in the edge of the region containing dislocations. However, detailed examination by TEM also showed a band of faceted voids at precisely this depth. These voids were larger than the voids in the shallower band. We suggest that $\mathrm{Au}$ is selectively decorating voids at this depth rather than loops. The fact that there is a deficiency of $\mathrm{Au}$ at depths between about 1500 and $2000 \AA$ and that this also corresponds to a region devoid of voids is intriguing. It appears that, at depths close to the boundary between vacancy and interstitial excesses, both voids and loops may coexist. The voids may be significantly larger because of the presence of loops which absorb the interstitials. Furthermore, this behavior may be more pronounced in our case compared with $\mathrm{MeV}$ implantation as a result of the close spatial proximity of vacancy and interstitial excesses. Whether point defects coalesce or annihilate may depend on their concentra- tion, the dose rate, and irradiation temperature. In the region denuded of voids (and Au decoration), this fine balance may have resulted in annihilation rather than coalescence into voids and interstitial clusters.

Finally, the observed $\mathrm{Si}^{+}$dose dependence of void formation as monitored by Au decoration leads to some interesting conclusions. For doses below about $3 \times 10^{15} \mathrm{~cm}^{-2}$ there is essentially no Au decoration of $R_{p} / 2$ defects, suggesting that the vacancy excess may be too dilute to form stable vacancy clusters and voids, or alternatively, such clusters do not survive annealing. The results for the 3 and 8 $\times 10^{15} \mathrm{~cm}^{-2} \mathrm{Si}^{+}$doses indicate that the number of excess vacancies per ion that contribute to stable voids on annealing is extremely low $(\sim 0.01)$. This number for $245 \mathrm{keV} \mathrm{Si}^{+}$ions at $100{ }^{\circ} \mathrm{C}$ is lower than that for $2 \mathrm{MeV} \mathrm{Si}$ at $70-80^{\circ} \mathrm{C}$ $(\sim 0.04)$ as obtained by Kalyanaraman et al. ${ }^{11}$

In conclusion, we have shown direct evidence for the formation of stable voids at $\leqslant R_{p} / 2$ for $245 \mathrm{keV} \mathrm{Si}^{+}$irradiation of $\mathrm{Si}$ at $100^{\circ} \mathrm{C}$, followed by annealing at $850{ }^{\circ} \mathrm{C}$. Furthermore, Au has a strong preference for decoration of voids rather than interstitial-based defects, indicating that $\mathrm{Au}$ is an excellent selective detector for open volume defects.

The authors are grateful to J. FitzGerald for discussion related to the TEM analysis. One of the authors (J.W.-L.) acknowledges the Australian Research Council for financial support.

${ }^{1}$ A. M. Mazzone, Phys. Status Solidi A 95, 149 (1986).

${ }^{2}$ D. J. Eaglesham, P. A. Stolk, H.-J. Gossmann, and J. M. Poate, Appl. Phys. Lett. 65, 2305 (1994).

${ }^{3}$ P. A. Stolk, J. L. Benton, D. J. Eaglesham, D. C. Jacobson, J.-Y. Cheng, J. M. Poate, S. M. Myers, and T. E. Haynes, Appl. Phys. Lett. 68, 51 (1996).

${ }^{4}$ J. L. Benton, S. Libertino, P. Kringhøj, D. J. Eaglesham, J. M. Poate, and S. Coffa, J. Appl. Phys. 82, 120 (1997).

${ }^{5}$ R. A. Brown, O. Kononchuk, G. A. Rozgonyi, S. Koveshnikov, A. P. Knights, P. Simpson, and F. Gonzales, J. Appl. Phys. 84, 2459 (1998).

${ }^{6}$ D. S. Zhou, O. W. Holland, and J. D. Budai, Appl. Phys. Lett. 63, 3580 (1993).

${ }^{7}$ S. L. Ellingboe and M. C. Ridgway, Nucl. Instrum. Methods Phys. Res. B 127, 90 (1997).

${ }^{8}$ W. O. Holland, L. Xie, C. Nielson, and D. S. Zhou, J. Electron. Mater. 25, 99 (1996)

${ }^{9}$ C. Szeles, B. Nielson, O. Asoka-Kumar, K. G. Lynn, A. Anderle, T. P. Ma, and G. W. Rubloff, J. Appl. Phys. 76, 3403 (1994).

${ }^{10}$ V. C. Venezia, D. J. Eaglesham, T. E. Haynes, A. Agarwal, D. C. Jacobson, H.-J. Gossmann, and F. H. Baumann, Appl. Phys. Lett. 73, 2980 (1998).

${ }^{11}$ R. Kalyanaraman, T. E. Haynes, V. C. Venezia, D. C. Jacobson, H.-J. Gossmann, and C. S. Rafferty, Appl. Phys. Lett. 76, 3379 (2000).

${ }^{12}$ R. Krause-Rehberg and H. S. Leipner, Appl. Phys. A: Mater. Sci. Process. 64, 457 (1997).

${ }^{13}$ J. Wong-Leung, E. Nygren, and J. S. Williams, Appl. Phys. Lett. 67, 416 (1995).

${ }^{14}$ D. M. Follstaedt, S. M. Myers, G. A. Petersen, and J. W. Medenach, J. Electron. Mater. 25, 151 (1966).

${ }^{15}$ R. Kögler, A. Peeva, W. Anwand, G. Brauer, W. Skorupa, P. Werner, and U. Gösele, Appl. Phys. Lett. 75, 1279 (1999).

${ }^{16}$ J. F. Ziegler, J. P. Biersack, and U. Littmark, The Stopping and Range of Ions in Solids (Pergamon, New York, 1985).

${ }^{17}$ J. Wong-Leung, J. S. Williams, A. Kinomura, Y. Nakano, Y. Hayashi, and D. J. Eaglesham, Phys. Rev. B 59, 7990 (1999).

${ }^{18}$ A. Uedono, T. Kitano, M. Watanabe, T. Moriya, T. Kawano, S. Tanigawa, R. Suzuki, T. Ohdaira, and T. Mikado, Jpn. J. Appl. Phys., Part 1 35, 2000 (1996).

${ }^{19}$ J. S. Williams, M. J. Conway, J. Wong-Leung, P. N. K. Deenapanray, M. Petravic, R. A. Brown, D. J. Eaglesham, and D. C. Jacobson, Appl. Phys. Lett. 75, 2424 (1999). 